\title{
Diversity and Inclusion: The Foundation for All Milestones
}

\author{
Tricia C. Elliott, MD; Steve Ko, MD
}

(Fam Med. 2020;52(6):459-60.)

doi: 10.22454/FamMed.2020.475552

G rowing up, I remember being the only one, or one of only a few kids of color throughout my classes. I recall feeling a mixed sense of relief, belonging, and shared experiences as I entered college and saw my black classmates who had similar stories and who were likewise encouraged to see other black faces looking back at them. When I entered medical school, the academic leadership proudly exalted the fact that our class had the largest number of black/African-American matriculants the school had ever seen, at 19 out of a class of 200 (16 women and three mennot a typo). As I have progressed through my career as a physician, academician, and leader, it saddens me to look around the room almost a half century into my life and still be the only one, or one of only a few. I know many of my colleagues of color may relate.

Within the circles of medical education, diversity and inclusion, along with health equity, have now taken center stage as core priorities. We realize the limited progress we have made in moving the diversity needle in medical education in the past 40 years, particularly in groups underrepresented in medicine (URM). We are committed to providing our learners the tools and resources needed to be competent physicians, including ensuring demonstration of core competencies and milestones we identify as essential; however, we may have failed our learners in the core competency foundational to all competencies and milestones: diversity and inclusion.

Last academic year, one of our incoming third-year family medicine chief residents, Steve Ko, MD, contacted me with an impassioned and thoughtful plea to partner in increasing our learner diversity. I was surprised and pleasantly struck by Dr Ko's personal story, his well-organized and informed plan, and his personal commitment to seeing more URM residents within our program; especially considering Dr Ko was not from a URM group. After listening to the efforts he had already independently undertaken to recruit more URM residents, I marveled at Dr Ko with heartfelt pride and excitement as I asked, "Why is this so important to you?" I was intrigued as he explained how having more diversity within our faculty and residents makes each resident and faculty a better physician and makes the care for our patients even better. He strongly felt it was the right thing for our patients and for one another.

My discussions and collaborations with $\mathrm{Dr}$ Ko have reminded me of the power of our learners in this journey toward inclusive excellence. More than ever, they desire their professional lives to reflect their personal lives in terms of the diversity they have grown to expect and respect. Our learners are crucial partners in advancing diversity and health equity, not only in what we teach them, but also what they impart to us as faculty.

My hope throughout my year as STFM president is to share stories from our membership (students, residents, and faculty) who are change agents and leading the way to breaking down barriers, building innovative strategies, and changing the landscape for diversity and inclusion in medical education. I often say that diversity cannot be accidental; it must be

From the John Peter Smith Health Network, Office of Academic Affairs, Ft Worth, TX (Dr Elliott); and the John Peter Smith Family Medicine Residency, Ft Worth, TX (Dr $\mathrm{Ko}$ ). 
intentional. It is the shared responsibility of us all. As we strategize to increase our diversity pool, address our selection biases, expand our community partnerships, and create sustainable support structures within our programs, departments, and organizations, we will need to remember that diversity is not only a priority, but an educational foundation.

\section{Steve Ko, MD}

I distinctly recall stepping into my third-grade classroom, being welcomed by a melting pot of 20 puzzled faces. I had just moved to the suburbs of Seattle from South Korea; and on that first day of American school, surrounded by foreign people whom I didn't think understood or cared for me, I was overwhelmed with one emotion: fear.

Fast forward a couple of decades, and I am entering a patient room, finding a middle-aged woman patiently awaiting my care. I learn that she is an immigrant like myself, but from a rural province in Mexico. As I explore her complaints and delve into her medical history, I recognize a familiar foe: fear. Except this time, I am encountering a fear external to myself. I can sense the apprehension in my patient's voice. Does this doctor really understand my concerns? Can I trust him to take care of me and my family?

Reflecting on my experiences in America, from setting foot in my first elementary school classroom to now daily entering the lives of my patients, I have come to appreciate the reality that my country, and its people, is powerfully diverse. On the surface, such diversity can admittedly be intimidating. It can be complicated by misunderstandings, discomfort, and even distrust. But diversity also presents an opportunity for growth. It has pushed me to both reconcile and celebrate differences with others, and to cherish the common qualities that unite us all as humans. It has stretched my patience and empathy, and it has demanded of me a more selfless love to offer friends and patients alike.

As the world globalizes and Americans continue to diversify in appearance, thought, and expressed identity, ${ }^{1}$ we as family physicians must adapt. We need to educate, equip, and encourage one another to meet the needs of our varied patient populations with greater sensitivity. We must individually examine our implicit biases while collectively working to correct the broader social and economic inequalities that have contributed to health care disparities in our nation. ${ }^{2,3}$ We also need to intentionally and relentlessly strive for diversity within our own institutions, granting patients the chance to be treated by those who can best relate to their cultures and identities. Through these processes, I believe we will all grow as physicians, being challenged by and learning from our patients and coworkers who look, think, and live differently from ourselves.

CORRESPONDING AUTHOR: Address correspondence to Dr Tricia Elliott, John Peter Smith Health Network, Academic Affairs, 1500 South Main St, Ft Worth, TX 76104 817-702-1173. TElliott@jpshealth.org.

\section{References}

1. Wilson SA. Diverse diversity. Fam Med. 2017;49(10):821-822.

2. FitzGerald C, Hurst S. Implicit bias in healthcare professionals: a systematic review. BMC Med Ethics. 2017;18(1):19.

3. Institute of Medicine. Unequal Treatment: Confronting Racial and Ethnic Disparities in Health Care. Washington: DC. National Academy Press; 2002. 